\title{
Patient-centredness versus achieving public health targets: A challenge for tuberculosis control
}

Fulfilling its aims, the paper by de Kok et al. (2018) illuminates complexities in delivering anti-retroviral therapy adherence support to HIV/AIDS patients. A key study finding about tensions between patient-centredness, trust, and performance targets resonates with our work on tuberculosis (TB). Like HIV, this is a potentially lethal infectious disease for which adherence to treatment is a critical challenge. While de Kok et al focus on adherence support delivered in clinical encounters between patients and health professionals (micro level) we highlight here issues with conflicting priorities operating at the policy (macro) level. Specifically, we reflect on years of policy research and informal discussions with TB policymakers in Asian low and middle-income countries (LMICS), which reveal ongoing struggles to achieve funders' performance targets while attaining equitable health gains for their populations (Khan \& Coker, 2014).

The Global Fund to Fight AIDS, Tuberculosis and Malaria - a major source of financing for national TB control programmes in LMICs - provides 'performance-based funding', which means that continued financial support is dependent on meeting pre-determined targets, including for TB treatment adherence and completion (The Global Fun, n.d.). When TB control programmes are considering expansion of TB services to under-served populations, such as those living in rural areas and conflict zones, policymakers are faced a difficult decision: do they prioritise unmet health needs and take on the risk that service delivery to hard to reach populations could jeopardise 'performance' against targets, and future funding? Our research team observed this situation in Myanmar in 2015, when drugresistant TB treatment was only available in one third of the country; there were clear tensions between the push to scale-up access to treatment, the lack of infrastructure to support scale-up in under-served areas, and the need to meet performance targets to secure future funding (The Global Fund, 2017; Khan et al 2017).

Ambitious goals and catchy branding are ingredients that allow a health issue to mobilise people and resources and ascend the public policy agenda, as a seminar paper in this journal documented over 15 years ago (Ogden, et al., 2003). This strategy has been adopted by Zero TB Cities, which is a new initiative focused on a bold target: to create 'islands of elimination' in selected cities in LMICs. A human rights angle was adopted to support the rationale for Zero TB Cities, on the basis that LMIC populations should have a 'access to the high standard of TB care that has been available for decades in Western Europe and North America' (Zero TB Cities; Nicholson, Admay, Shakow, \& Keshavjee, 2016). While this initiative appears to have had initial success in attracting political attention and resources, we are concerned that pouring resources into eliminating TB from defined urban areas is likely to magnify urban-rural inequalities in target countries. 
In closing we would like to congratulate de Kok et al. for shedding light on an important, but poorly addressed, issue for HIV/AIDS control, and suggest that their findings are relevant more broadly. For us, this paper emphasised that when global health is framed in terms of a race to meet targets, it begins to shape the way we view long-term solutions to pressing health problems. We may start to believe that those who do not adhere to treatment, in the rural areas, in the migrant camps, put everyone else at risk. We may stop questioning why certain approaches to treatment do not work for some population groups. In an era when public health targets are becoming more prominent, we may benefit from remembering that not everything that can be counted counts and not everything that counts can be counted.

\section{References}

Khan, Mishal S., and Richard J. Coker. "How to hinder tuberculosis control: five easy steps." The Lancet 384.9944 (2014): 646-648.

Khan, Mishal S., et al. "Large funding inflows, limited local capacity and emerging disease control priorities: a situational assessment of tuberculosis control in Myanmar." Health policy and planning 32.suppl_2 (2017): i22-i31.

Nicholson T, Admay C, Shakow A, Keshavjee S. Double Standards in Global Health: Medicine, Human Rights Law and Multidrug-Resistant TB Treatment Policy. Health and Human Rights. 2016;18(1):85-102.

Ogden, J. et al. 2003 The politics of 'branding' in policy transfer: The case of DOTS for tuberculosis control. Social Science \& Medicine 57(1): 179-188.

The Global Fund. www.theglobalfund.org/en/financials/ [accessed 10 May 2018]

The Global Fund Programme in Myanmar (2017). https://prmyanmar.org/en/resultgraph/tb-programme-achievements-2017 [accessed 10 May 2018]

Zero TB Cities www.zerotbinitiative.org/ [accessed 10 May 2018] 